\title{
INVESTIGAÇÕES A RESPEITO DA SITUAÇÃO DE COMUNICAÇÃO DOS AKWẼ-XERENTE SURDOS
}

\author{
BARRETOS $^{1}$, Euder Arrais \\ Universidade Federal de Goiás (UFG)
}

\section{RESUMO}

Este artigo objetiva socializar alguns resultados a respeito da investigação sobre a situação de comunicação em que se encontram os Akwẽ-Xerente Surdos. Em relação à metodologia de pesquisa foram consideradas as abordagens qualitativa (DENZIN, LINCOLN, 2006; LÜDKE, ANDRÉ, 1986) e quantitativa: a pesquisa bibliográfica, de levantamento e o estudo de campo. Os fundamentos teóricos que embasaram a pesquisa foram, entre outros, as concepções de surdez em Skliar (2005), as noções de enunciado baseadas em Bateson (2002), Martin-Barbero (1991), Bakhtin (1997) e Freire (1987). Quanto à análise sociolinguística dos Akwẽ-Xerente, foram considerados os dados gerados pelos estudos feitos por Lopes e Farias (1992), Guimarães (2002), Schroeder (2010), Cotrim (2011), Mesquita (2015) e por minha pesquisa de campo. Esta pesquisa registrou a presença de treze Surdos entre 07 e 62 anos de idade residindo em 10 aldeias desse povo e evidenciou as formas de comunicação entre Surdo-Surdo e Surdoouvinte, além do acesso dos Surdos às práticas culturais de seu povo.

Palavras-chave: Akwẽ-Xerente. Comunicação. Surdos.

\section{ABSTRACT}

This article aims to socialize some results regarding the research on the communication situation in which the Akwẽ-Xerente Deaf people are. In relation to the research methodology, qualitative approaches (DENZIN, LINCOLN, 2006; LÜDKE, ANDRÉ, 1986) and quantitative ones were considered: bibliographical research, survey and field study. The notion of deafness in Skliar (2005), the notions of communication based on Bateson (2002), Martin-Barbero (1991), Bakhtin (1997) and Freire (1987)

1 Graduação em Pedagogia pela Universidade Federal de Goiás (1996). Pós-graduação em Educação Infantil (PUC-GO/2002). Pós graduação em Atendimento Educacional Especializado -AEE (UFC/2010). Mestre em Letras e Linguística pela Universidade Federal de Goiás (2016). Email: euder.arrais@gmail.com 
are the basis for this study. As for the sociolinguistic analysis of the Akwẽ-Xerente, the data generated by studies by Lopes and Farias (1992), Guimarães (2002), Schroeder (2010), Cotrim (2011) and Mesquita (2015). The research recorded the presence of thirteen Deaf people aged between 07 and 62 residing in 10 villages of this people and evidenced the forms of communication between Deaf-Deaf and Deaf-listener, as well as the deaf people's access to the cultural practices of their people.

Key words: Akwẽ-Xerente. Comunication. Deaf.

\section{INTRODUÇÃO}

No contato direto com os Akwẽ-Xerente em suas terras e durante o Curso de Especialização Intercultural e Transdisciplinarpara professores indígenas que já concluíram o Curso de Licenciatura em Educação Intercultural, ambos oferecidos pela Universidade Federal de Goiás (UFG) exclusivamente para os povos indígenas, escutando suas histórias e depoimentos, pude conhecer sobre sua organização social, cultura, cosmologia, sistema de parentesco, educação e, nesse contexto, sobre a situação de alguns Akwẽ-Xerente Surdos.

Assim sendo, entendendo ser relevante o desenvolvimento de pesquisas nessa área que possam acrescentar ao debate sobre a situação dos indígenas Surdos no Brasil, suas formas de comunicação, suas línguas, entre outros, criando-se, assim, outras referências que, de fato, subsidiem novas demandas de pesquisas nessa área, intensifiquei os estudos sobre aquele povo e propus o projeto de investigação sobre a situação de comunicação dos AkwẽXerente Surdos.

Considerando o exposto, diante da necessidade de se ampliarem as discussões a respeito da temática, objetivando evidenciar as características da comunicação dos Akwẽ-Xerente Surdos, tornou-se relevante a identificação, o registro, a descrição e a análise da situação de comunicação em que eles estão inseridos. Tal situação abrange as formas de comunicação no dia a dia e nas festas culturais, com a família e com a comunidade, as práticas educacionais, considerando os relatos dos colaboradores da pesquisa em relação às interações comunicativas entre Surdo-Surdo e Surdo-ouvinte, entre outros fatores inerentes ao processo de desenvolvimento e aprendizagem dos Surdos nas ambiências culturais desse povo. 
Nesse sentido, esse artigo objetiva socializar alguns resultados de uma pesquisa feita por mim sobre a situação comunicativa dos Akwẽ-Xerente Surdos, na busca de novos saberes e construtos teóricos que pudessem contribuir para o desenvolvimento de políticas públicas voltadas para a implementação de uma educação que atenda à demanda desse público.

Utilizo para este trabalho o termo Surdo [com S maiúsculo]. Essa terminologia não significa a "falta" de audição, tampouco se refere a uma visão estereotipada de seres isolados, incomunicáveis, desprovidos de inteligência, adultos infantilizados ou de pessoa "deficiente", seja auditiva ou intelectualmente. Quando comumente se pensa a respeito do mundo da surdez, imagina-se um mundo sem som.

Parafraseando Marleu-Ponty (1975), eu imagino aquele mundo cheio de possibilidades, no qual pessoas clarividentes interagem, significam o mundo, aprendem, se desenvolvem e se expressam através de um canal de comunicação visual-espacial, cuja experiência sociocultural é uma experiência visual (SACKS, 1998). Seguindo esse entendimento, os Surdos, ao contrário de serem considerados "deficientes", são seres cheios de possibilidades de interação comunicativa. Nesse contexto também se inserem os indígenas, para os quais as representações visuais carregam informações e saberes passados ao longo das gerações, resultando em um conjunto de elementos identitários e de memória de um povo.

Todas essas considerações me levaram a indagar, durante a pesquisa: o que demonstram os registros estatísticos sobre a quantidade de Akwẽ-Xerente Surdos? Em quais aldeias eles vivem? Como acontece a comunicação entre os Akwẽ-Xerente Surdos e entre eles e os ouvintes? Qual a representação de surdez do povo AkwẽXerente? Quais os processos próprios de educação do povo AkwẽXerente? Quais as expectativas de aprendizagem dos Akwẽ-Xerente Surdos pelo seu povo? Como tem acontecido o seu acesso aos bens culturais de seu povo e à educação escolar indígena? Enfim, como lhes tem sido garantida a prática de cidadania enquanto cidadãos Akwẽ-Xerente?

A metodologia adotada durante a realização da pesquisa foi um tecer constante, sempre que a realidade me era, aos poucos, evidenciada. Dessa forma, diversificada e específica a cada etapa do estudo, foi sendo estabelecida considerando-se: 1) a relação dialógica entre o meu contato com os Akwẽ-Xerente; 2) as 
etnografias disponíveis; 3) os estudos teóricos, os quais foram se fazendo presentes e norteando o trabalho durante toda a pesquisa. Essa dialogia me permitiu elencar, com mais segurança e clareza, a base teórica necessária para as análises e interpretação dos dados que me foram sendo apresentados pela pesquisa, bem como a forma de descrição dos resultados desse processo investigativo.

Portanto, para a pesquisa, utilizei a revisão bibliográfica, a observação e conversas pessoais durante o Curso de Especialização Intercultural e Transdisciplinar oferecido pela UFG, bem como nos momentos de meu trabalho de campo nas aldeias Akwẽ, além de entrevistas semiestruturadas com professores Akwẽ que frequentam o referido curso.

Ao considerar as palavras de Nelson Praze Xerente, para quem "fazer uma pesquisa [sobre os Surdos] no meio dos Akwẽ é importante, é um direito nosso" e, dessa forma, poder propiciar-lhes uma melhor acessibilidade às vivências e práticas tradicionais, às práticas de cidadania enquanto cidadãos Akwẽ-Xerente, espera-se com a socialização deste trabalho contribuir com a demanda pelos estudos a respeito da situação de comunicação dos Akwẽ-Xerente Surdos e ainda colaborar com o debate nacional sobre a situação sociolinguística dos indígenas Surdos no Brasil.

\section{A situação de comunicação dos Akwẽ-Xerente surdos}

De acordo com Wewering (2012), há atualmente 3.210 AkwẽXerente, divididos em 57 aldeias habitando duas áreas situadas no Estado do Tocantins à margem direita do rio Tocantins, município de Tocantínia, a 80 quilômetros da cidade de Palmas. Mesquita (2015) informa a existência de 3.600 indivíduos, em 66 aldeias. Pude verificar através de trabalho de campo que, atualmente, o povo Akwẽ-Xerente, apesar de não saber precisar dados mais recentes em relação à sua população, informa que se somam 64 aldeias entre seu povo, em duas áreas demarcadas pelo Estado Brasileiro. A primeira área, denominada Terra Indígena Xerente, possui 167.542 hectares e, a segunda, contígua à primeira, denomina-se Terra Indígena Funil, com 16.000 hectares.

Quanto à organização sociocultural, o Povo Akwẽ se organiza em seis clãs divididos em duas metades Doí e Wahirê, associados ao sol e à lua: Krito Tdêkwa, Kbazi Tdêkwa, Kuzâp Tdêkwa, e Krozake 
Tdêkwa, Wahirê Tdêkwa e Krẽpre Tdêkwa (COTRIM, 2011). Cada clã possui uma pintura corporal própria como forma de identificação de pertencimento a uma determinada organização social, entre outros. Os Akwẽ consideram importante o respeito entre os clãs e as metades. Esse respeito é uma forma de manutenção e organização da vida em sua sociedade.

No que se refere aos aspectos sociolinguísticos, o povo Akwẽ-Xerente forma, com os Xavantes e os Xakriabá, o ramo central das sociedades de língua Jê (SCHROEDER, 2010). Segundo Rodrigues (1986), os Akwẽ-Xerente pertencem ao tronco linguístico denominado Macro-Jê e à família linguística denominada Jê. De acordo com o autor, nesse tronco são incluídas ainda seis famílias genéticas (Jê, Bororo, Botocudo, Karajá, Maxakali, Pataxó) além de quatro línguas (Guató, Ofayé, Rikbaktsá e Yatê/Fulniô). As línguas filiadas a esse tronco, exclusivamente brasileiro, são faladas principalmente nas regiões de campos e cerrados, desde o sul do Maranhão e Pará, passando pelos estados do Centro-Oeste até Estados do Sul do país (SEKI, 1999).

Segundo o próprio povo Akwẽ-Xerente, o nome Xerente lhes foi dado por não indígenas para diferenciá-los particularmente dos Xavantes. O nome Akwẽ pode ser traduzido para o português como 'o que está acima de todas as coisas', 'o mais notável', 'o que é humano, gente'. Quanto a essa tradução, pude presenciar que esse povo se autodenomina de 'gente importante'.

No território Akwẽ-Xerente existem povos indígenas falantes de diferentes línguas. Conforme estudos feitos por mim em território Akwẽ e com os professores indígenas, essas línguas são: Akwẽ, Português, Javaé, Krahô, Xavante, Karajá, Xakriabá, Guajajara, Krikati, Apinajé, Guarani, Bororo, ou seja, é um território multilíngue. Essa realidade sociolinguística se deve ao casamento interétnico, tanto por parte dos homens quanto das mulheres, com integrantes de outros povos indígenas e não indígenas. Dessa forma, os novos integrantes do mundo Akwẽ, que trazem consigo suas línguas e seus costumes, aprendem a se comunicar primeiramente naquela comunidade fazendo o uso da língua portuguesa (LP) e, aos poucos, na medida em que se intensifica o contato cultural, vão aprendendo a língua Akwẽ.

Sobre o uso linguístico nos domínios sociais entre os AkwẽXerente, de acordo com Guimarães (2002), e também com o que pude constatar através da pesquisa, há uma predominância da Língua 
Akwẽ nas diversas esferas das relações sociais, ou seja, o Akwẽ é a língua mais falada naquele território, utilizada nas atividades do dia a dia, nas escolas, nas reuniões e nas festas culturais. O uso da LP é dominante na função de língua escrita e na interação com os não indígenas, que é a situação de uso dessa língua. Sinã:

Essa situação do bilinguismo é confirmada pelos estudos de

A língua mãe do meu Povo e a língua portuguesa têm suas funções bem distintas, como, por exemplo, o português é importante sim para nós, mas isso não significa que ela veio para tomar lugar da nossa língua mãe e sim para ser usada em ocasiões diferentes. (SINÃ, 2012, p. 66)

A partir desses estudos, pode-se inferir que a atitude linguística dos Akwẽ-Xerente é de um bilinguismo de manutenção da língua materna e do uso da língua portuguesa nas realidades que reivindicam esse comportamento linguístico.

Os Surdos estão inseridos nesse contexto sociolinguístico. Os seus primeiros contatos são, portanto, com sua família de ouvintes que faz uso de uma língua de modalidade oral-auditiva, que, nesse caso, é a língua Akwẽ, mas que também faz uso de gestos, como em toda situação de comunicação humana.

Em situações comunicativas com a presença de pessoas de outras etnias ou de não indígenas e, mais tarde, na escolarização, entram em contato ainda com outra língua de mesma modalidade oral, a língua portuguesa.

Após a detecção da surdez, estando imersos nessa gama de possibilidades comunicativas, esses sujeitos ainda lançam mão de uma modalidade visuoespacial de comunicação, considerando os casos de uso de sinais e gestos criados por seus familiares. Ou seja, a realidade sociolinguística dos Akwẽ-Xerente possibilitou este estudo evidenciar aspectos da comunicação especificamente dos Surdos.

No tocante ao processo de comunicação humana, de forma geral, Martin-Barbero (1991, p. 228), entendendo ser fundamental a compreensão da importância da natureza comunicativa, ressalta "seu caráter de processo produtor de significações e não de mera circulação de informações, no qual o receptor, portanto, não é um simples decodificador daquilo que o emissor depositou na mensagem, mas também um produtor". 
Freire (1987) entende o processo de comunicação enquanto ação dialógica entre os sujeitos, mediatizados pela realidade cultural, pela vivência das experiências em comum. Na teoria de Bakhtin (1997, p. 293), o ato comunicacional também é visto como atividade social, marcado pelo diálogo, pela possibilidade de interação entre os sujeitos:

A fala só existe, na realidade, na forma concreta dos enunciados de um indivíduo: do sujeito de um discurso-fala. $\mathrm{O}$ discurso se molda sempre à forma do enunciado que pertence a um sujeito falante e não pode existir fora dessa forma. Quaisquer que sejam o volume, o conteúdo, a composição, os enunciados sempre possuem, como unidades da comunicação verbal, características estruturais que lhes são comuns, e, acima de tudo, fronteiras claramente delimitadas (grifo do autor).

Dessa forma, o enunciado é visto como produto da interação verbal, determinado tanto por uma situação material concreta como pelo contexto. Assim sendo, o enunciado não pode ser compreendido dissociado das relações sociais que o suscitaram, pois o "discurso", como fenômeno de comunicação social, é determinado por tais relações. Ou seja, essa noção de enunciado como um todo de sentido não se limita apenas à sua dimensão linguística, mas concebe a situação social (ou dimensão extraverbal) como elemento constitutivo (CAVALCANTE FILHO; TORGA, 2011).

Ressalte-se, nessa direção, que, segundo Felipe (2013, p. 67), os pressupostos teóricos bakhtinianos "podem reforçar a argumentação de que, em enunciados de línguas de modalidade gestual visual, transparecem valores plásticos picturais dos signos através também das Marcas não Manuais”. Segundo a autora,

[...] a constatação de uma comunicação verbo visual, através de imagens e outros recursos gráficos em textos escritos está ampliando os horizontes das pesquisas linguísticas com a articulação do verbal e do não verbal sob um enfoque discursivo e sob uma perspectiva do círculo de Bakhtin, como as pesquisas de Geraldi (1991), Brait (2004, 2005 e outros), Grillo (2009, 2013), Berti-Santos (2011, 2013), entre outros (FELIPE, 2013, p. 73). 
Portanto, para a realização da pesquisa, o Ser Surdo é considerado um ser diferente cuja experiência com o mundo é uma experiência visual, não sendo, inclusive, minorizada ou inferiorizada. O conceito de diferença, como diz Skliar (2005, p. 6), não é aqui utilizado como um termo a mais, tal como, por exemplo, "deficiência", pois este, no geral, mascara e neutraliza as possíveis consequências políticas e se revela como estratégia conservadora para ocultar uma intenção de normalização:

A diferença, como significação política, é construída historicamente e socialmente; é um processo e um produto de conflitos e movimentos sociais, de resistência às assimetrias de poder e de saber, de uma outra interpretação sobre a alteridade e sobre o significado dos outros no discurso dominante.

Dessa forma, a especificidade da modalidade visuoespacial de comunicação de Surdos, que se utiliza de gestos, posturas, formas verbais e não verbais, bem como a existência de várias línguas de modalidade oral auditiva em sua comunidade, entre outros, nos leva ao reconhecimento da existência de um contexto sociolinguisticamente complexo entre surdo versus ouvinte e surdo versus surdo no território Akwẽ.

Feitas essas considerações, percebe-se, em estimativa, a existência de Surdos entre os Akwẽ com perda auditiva bilateral, acima de quarenta e um decibéis $(\mathrm{dB})$ ou mais, considerada perdas auditivas moderadas, severas ou profundas. Essa estimativa se deve ao fato da não identificação entre os Surdos Akwẽ de exames de audiometria que detectam a percepção dos sons.

Quanto à quantidade de Surdos Akwẽ, a pesquisa evidenciou a existência de sujeitos de várias faixas etárias e de ambos os sexos. A tabela a seguir apresenta melhor os dados dessa realidade, elencados por mim na terra indígena Akwẽ.

\section{Tabela 1}

Quantidade de Surdos, com faixa etária, por aldeia.

\begin{tabular}{ccccc}
\hline $\begin{array}{c}\text { Nome da } \\
\text { Aldeia }\end{array}$ & $\begin{array}{c}\text { Nome do } \\
\text { Cacique }\end{array}$ & $\begin{array}{c}\text { Nome do } \\
\text { Surdo }\end{array}$ & $\begin{array}{c}\text { Idade do } \\
\text { Surdo }\end{array}$ & $\begin{array}{c}\text { Quantidade } \\
\text { de Surdos } \\
\text { por aldeia }\end{array}$ \\
\hline
\end{tabular}




\begin{tabular}{|c|c|c|c|c|}
\hline \multirow{3}{*}{ Aldeia Salto } & \multirow{3}{*}{ Valci Sinã } & A & 35 & \multirow{3}{*}{03} \\
\hline & & G & 25 & \\
\hline & & $\mathrm{N}$ & 20 & \\
\hline \multirow{2}{*}{$\begin{array}{c}\text { Aldeia Brejo } \\
\text { Comprido }\end{array}$} & \multirow[b]{2}{*}{ Isaias Sizapi } & $\mathrm{B}$ & 07 & \multirow{2}{*}{02} \\
\hline & & $\mathrm{I}$ & 18 & \\
\hline $\begin{array}{l}\text { Aldeia } \\
\text { Paraíso }\end{array}$ & Adão Wdêrêhu & M & 18 & 01 \\
\hline $\begin{array}{l}\text { Aldeia } \\
\text { Porteira }\end{array}$ & $\begin{array}{c}\text { Antônio Samuru } \\
\text { (Diretor da } \\
\text { escola) }\end{array}$ & $\mathrm{K}$ & 61 & 01 \\
\hline $\begin{array}{c}\text { Aldeia } \\
\text { Lajeado }\end{array}$ & Sergio Sitrê & $\mathrm{C}$ & $\begin{array}{c}\text { Não } \\
\text { informado }\end{array}$ & 01 \\
\hline $\begin{array}{l}\text { Aldeia } \\
\text { Serrinha }\end{array}$ & $\begin{array}{c}\text { Severino } \\
\text { Damsõihâ }\end{array}$ & $\mathrm{F}$ & $\begin{array}{c}\text { Não } \\
\text { informado }\end{array}$ & 01 \\
\hline $\begin{array}{l}\text { Aldeia } \\
\text { Coqueiro }\end{array}$ & $\begin{array}{c}\text { Paulo } \\
\text { Wakezane }\end{array}$ & $\mathrm{S}$ & 12 & 01 \\
\hline $\begin{array}{l}\text { Aldeia Rio } \\
\text { Preto }\end{array}$ & Bento Wakuke & $\mathrm{D}$ & 62 & 01 \\
\hline $\begin{array}{l}\text { Aldeia Rio } \\
\text { Sono }\end{array}$ & $\begin{array}{l}\text { Arnaldo } \\
\text { Srẽmtôwẽ }\end{array}$ & $\mathrm{H}$ & 61 & 01 \\
\hline $\begin{array}{l}\text { Aldeia Boa } \\
\text { Esperança }\end{array}$ & Valmir Srõzdazê & $\mathrm{N}$ & 62 & 01 \\
\hline TOTAL & & & & 13 \\
\hline
\end{tabular}

Fonte: Dados obtidos pelo pesquisador

Conforme é indicado na tabela 1, este estudo evidenciou a quantidade de 13 Surdos entre 07 e 62 anos de idade, residindo em dez aldeias desse povo: Aldeia Salto, Aldeia Brejo Comprido, Aldeia Paraíso, Aldeia Porteira, Aldeia Lajeado, Aldeia Serrinha, Aldeia Coqueiro, Aldeia Rio Preto, Aldeia Rio Sono e Aldeia Boa Esperança.

Considerando as poucas aldeias em que reside mais de um Surdo, bem como a distância entre elas, em consequência disso, há poucas oportunidades de encontros entre eles, ou seja, de participarem 
do mesmo contexto de enunciação, a não ser nos momentos das festas culturais, como a festa anual de nomeação, chamada de Dasĩpê.

Considere-se ainda, para esses contatos, a variedade de faixas etárias entre eles. Assim como acontece com os ouvintes, os Surdos também estão sujeitos, ao se encontrarem, às influências interacionais advindas das diferenças geracionais, do fato de participarem de grupos diferentes que, inclusive, trazem consigo certa variação linguística, dependendo das distâncias entre as aldeias e entre essas e as populações não indígenas (SILVINO XERENTE) e também por integrarem clãs diferentes.

A comunicação entre Surdo-ouvinte em cada aldeia, nas atividades do dia a dia, acontece, na maioria das vezes, com mais intensidade, dentro da própria família, pois há ali uma criação de gestos e sinais de comunicação para serem utilizados primeiramente naquele contexto e que são pouco divulgados para a comunidade em geral. Essa realidade demonstra uma interação comunicativa entre os Surdos e os ouvintes, com o uso de sinais, mais restrito ao seio familiar.

Em relação à comunicação entre Surdo-Surdo, com o uso dos sinais Akwẽ que cada família vai construindo, verifiquei que não há muita interação entre eles nas atividades do dia a dia nas aldeias e durante as festas culturais, momento em que integrantes de várias aldeias se reúnem e há intensa interação comunicativa entre todos.

Pelo que indicou a pesquisa, isso se deve a alguns fatores: 1) não haver uma comunidade de Surdos devido à existência de poucos Surdos por aldeia, pela grande quantidade de aldeias e a distância entre elas; 2) os Surdos já estarem acostumados a se comunicarem, com o uso de gestos e sinais, entre os integrantes da própria família; 3) a comunicação entre Surdos e ouvintes ser tida como natural e corriqueira entre os Akwẽ, mesmo sem o uso mais intenso de sinais e gestos como é feito pelas famílias dos Surdos. Isso faz com que não haja uma tendência dos Surdos em procurarem se relacionar entre si, como é comum na sociedade não indígena; 4) a presença de Surdos com deficiências ou transtornos, tais como o autismo [embora se tenha constatado apenas a presença de um integrante com essa característica, pode ser que haja mais casos como esse]; 5) a linguagem corporal ser bem desenvolvida e fazer parte da própria organização sociopolítica Akwẽ-Xerente, o que lhes propicia uma gama de possibilidades comunicativas que não são limitadas ao uso dos enunciados na língua oral. 
Assim sendo, a realidade sociolinguística evidenciada com a pesquisa demonstra uma determinada forma de comunicação entre Surdos e ouvintes, bem como entre os próprios Surdos de aldeias diferentes, pelo fato daqueles sinais serem criados pelas famílias dos Surdos, sem que sejam socializados/convencionalizados e passem a ser utilizados pela comunidade.

Nessa perspectiva, a pesquisa com os Akwẽ evidenciou um desejo desse povo de que os Surdos possam ser ainda mais ativos, mais autônomos, mais incluídos em todas as atividades do dia a dia, nas ocasiões das festas culturais, entre outras. O professor Gilberto Xerente demonstra, em seu depoimento, a expectativa que seu povo tem em relação a isso:

\footnotetext{
[...] eu acho que são capazes [de aprender] sim pelo que eu entendo, pelo que eu vejo... eu tô falando isto porque os surdos, parece que eles têm essa comunicação de alguns sinais, a gente usa os sinais... acho que eles têm capacidade sim de aprender.
}

Para esse intento, esse povo chama a atenção para a necessidade de um melhor entendimento a respeito das especificidades da comunicação dos Surdos e de suas possibilidades de aprendizagem.

\section{CONCLUSÃO}

Este estudo evidenciou as formas próprias de ver e estar no mundo dos Akwẽ-Xerente, a existência de Surdos entre eles, a faixa etária, a nominação e a localização das aldeias onde vivem, as formas de comunicação entre Surdo-Surdo e Surdo-ouvinte, além do acesso dos Surdos às práticas culturais de seu povo.

O entendimento a respeito da cultura do povo Akwẽ-Xerente, a partir dos estudos, dos relatos e a realidade observada, bem como o referencial teórico abordado na pesquisa permitiram evidenciar as características da comunicação dos Surdos desse povo, pois propiciaram a compreensão sobre a apropriação do mundo a partir da visão, da expressão corporal e facial, da comunicação não verbal, entre outras tantas outras possibilidades de interação comunicativa humana e que estão muito presentes na cultura desse povo.

Entre os Akwẽ, a epistemologia é de acesso a todos, registrado inclusive no próprio corpo e os Surdos têm acesso a esse conhecimento 
que está disponível a qualquer um. $\mathrm{O}$ acesso aos conhecimentos, aos saberes presentes nas vivências culturais desse povo, também deve ser considerado no processo de escolarização por meio da utilização de recursos visuais, imagens e pela representação dos rituais. $\mathrm{Ou}$ seja, os conhecimentos podem ser vivenciados, aprendidos e internalizados por todos sem que seja necessário o uso exclusivo da oralização. O que se aprende, considerando essas estratégias didático-metodológicas, é internalizado de tal forma que nunca mais é esquecido e, com isso, os saberes são fortalecidos, contribuindose para a valorização e manutenção das tradições culturais e para o acesso de novos saberes.

É importante que se possibilite compreender os conhecimentos que os educandos Surdos trazem consigo e a participação de familiares nesse processo é bastante enriquecedora. Nesse entendimento, a apropriação e divulgação pela escola dos sinais Akwẽ trazidos pelos Surdos são imprescindíveis para a ampliação das possibilidades de comunicação entre todos, para a valorização cultural e a melhoria da autoestima tão preciosa no processo de aprendizagem de qualquer sujeito.

Portanto, fica bastante evidente com este estudo a grande possibilidade de interação comunicativa propiciada pelas práticas culturais dos Akwẽ-Xerente e, por outro lado, a necessidade de se investigar ainda mais a respeito da comunicação entre Surdoouvinte e Surdo-Surdo, com uma análise exaustiva dos sinais Akwẽ utilizados entre eles, a partir de pesquisas realizadas tanto pelos não indígenas quanto pelo próprio povo Akwẽ, considerando os espaços de produção cultural e de uso dos sinais, bem como toda a discussão a respeito dos "sinais caseiros" e da concepção de língua debatidos em outros estudos sobre os indígenas Surdos no Brasil. A esse respeito, como reflexão final a partir dessa etapa do estudo feito, ao evidenciar a presença de sinais Akwẽ, indaga-se a respeito da existência de uma Língua de Sinais Akwẽ-Xerente.

Muitos aspectos relacionados aos Surdos Akwẽ-Xerente ainda carecem de investigação, fato esse que evidencia a necessidade de que outras pesquisas possam ser desenvolvidas, inclusive pelos próprios integrantes desse povo. Como exemplo disso, cito a demanda de pesquisa sobre o levantamento da totalidade de Surdos Akwẽ, bem como o mapeamento dos sinais utilizados por eles.

Outras investigações se fazem necessárias em relação às características da comunicação dos Surdos Akwẽ-Xerente, tais como investigação a respeito do sentimento do próprio Surdo em relação 
à situação de comunicação em que se encontra, a análise do impacto do processo de aprendizagem da Libras pela comunidade Akwẽ, o processo de escolarização dos Surdos, suas práticas pedagógicas e os materiais didáticos utilizados, propiciando a elaboração de metodologias próprias para as salas de aulas das escolas AkwẽXerente com Surdos e ouvintes matriculados, entre outros.

Assim sendo, espero que esta investigação a respeito dos Akwẽ-Xerente Surdos possa contribuir no sentido de possibilitar a eles e também aos ouvintes outras tantas oportunidades de interação comunicativa e de aprendizagem, ou seja, práticas de cidadania voltadas para sua autonomia e atuação sociocultural crítica.

\section{REFERÊNCIAS}

BAKHTIN, M. Estética da criação verbal. $2^{\mathrm{a}}$ ed. Martins Fontes: São Paulo, 1997.

CAVALCANTE FILHO, U; TORGA, V. L. M. Língua, discurso, texto, dialogismo e sujeito: compreendendo os gêneros discursivos na concepção dialógica, sócio histórica e ideológica da língua(gem). In: CONGRESSO NACIONAL DE ESTUDOS LINGUÍSTICOS, 1., 2011, Vitória. Anais... Vitória: [s.n.], 2011. Disponível em: <www.periodicos.ufes.br/coneiasl/ article/download/2014/1526>. Acesso em: 22 set. 2015.

COTRIM, R. G. P. M. Romawihku Akwẽ-Xerente, Português, English: Diálogo Intercultural no Ensino-Aprendizagem do Inglês (L3) para professores indígenas. 2011. 305 f. Dissertação (Mestrado em Estudos Linguísticos) Faculdade de Letras, Universidade Federal de Goiás, Goiânia, 2011.

FELIPE, T. A. O discurso verbo-visual na língua brasileira de sinais Libras. Bakhtiniana, São Paulo, v. 8, n. 2, p. 67-89, 2013. Disponível em: $<$ http://www.scielo.br/pdf/bak/v8n2/05.pdf>. Acesso em: 1 out. 2015.

FREIRE, P. Pedagogia do Oprimido. 17ª ed. São Paulo: Paz e Terra, 1987.

GUIMARÃES, S. M. G. A Aquisição da Escrita e Diversidade Cultural: a prática dos Professores Xerente. Brasília: FUNAI/DEDOC, 2002.

MARLEU-PONTY, M. O Olho e o espírito. São Paulo: Abril Cultural, 1975.

MARTIN-BARBERO, J. De los médios a las mediaciones: comunicación, cultura y hegemonia. 2. ed. México: Editorial Gustavo Gili, 1991.

MESQUITA, R. Code-switching em Akwe-Xerente/Português. 2015. 242 f. Tese (Doutorado em Estudos Linguísticos) - Faculdade de Letras, Universidade Federal de Goiás, Goiânia, 2015. 
RODRIGUES, A. D. I. Linguas brasileiras: para o conhecimento das línguas indígenas. São Paulo: Loyola, 1986.

SACKS, O. W. Vendo Vozes: uma viagem ao mundo dos surdos. São Paulo: Companhia das Letras, 1998.

SEKI, L. A Linguística Indígena no Brasil. Revista DELTA, vol. 15, n. especial, 1999. Disponível em: <http://www.scielo.br/scielo.php?pid=S0102-44501999000300011\&script =sci_arttext>. Acesso em: 12 jul. 2014.

SCHROEDER, I. Os Xerente: estrutura, história e política. Soc. e Cult., Goiânia, v. 13, n. 1, p. 67-78, jan./jun. 2010. Disponível em: <http://www. revistas.ufg.br/index.php/fchf/article/ download/11174/7337>. Acesso em: 17 out 2014.

SINÃ, V. Diferença entre damrme (fala) dos mais velhos (wawe) e dos mais jovens (wapte) RELATÓRIO DO OBSERVATÓRIO DA CAPES. Núcleo Takinahakỹ de Formação Superior de Professores Indígenas. Universidade Federal de Goiás, Goiânia, 2012. p. 66-74

SKLIAR, C. (Org.). Surdez: um olhar sobre as diferenças. Porto Alegre: Mediação, 2005.

WEWERING, S. T. (Org.). O Povo Akwẽ Xerente: vida, cultura, identidade. Belo Horizonte: Rona, 2012. 